\title{
Identifikasi Dimensi-Dimensi Work-Life Balance pada Karyawan Generasi Milenial di Sektor Perbankan
}

\author{
Seta A Wicaksana ${ }^{1}$, Suryadi ${ }^{2}$, Aisyah Pia Asrunputri ${ }^{3}$ \\ ${ }^{1,2}$ Fakultas Psikologi, Universitas Pancasila \\ Jl. Srengseng Sawah, Jagakarsa - Jakarta Selatan \\ e-mail: ${ }^{1}$ seta.wicaksana@univpancasila.ac.id, ${ }^{2}$ ysur147@gmail.com \\ ${ }^{3}$ Sekolah Pascasarjana Universitas Pancasila \\ Jl. Borobudur, Jakarta 10310 \\ e-mail: aisyahpia@yahoo.com
}

\begin{abstract}
Abstrak - Generasi milenial dalam bekerja tidak hanya berfokus pada tingkat penghasilan yang tinggi, akan tetapi mereka juga mempertimbangkan kondisi yang seimbang antara pekerjaan dan kehidupan pribadi mereka. Ketika generasi milenial mendapatkan tempat kerja yang sesuai yang diinginkan dapat meningkatkan kepuasan dalam bekerja yang akan berdampak pada peningkatan kinerja. Tujuan dari penelitian ini adalah untuk mengidentifikasi dimensi-dimensi work-life balance pada karyawan generasi milenial di sektor perbankan. Variabel work-life balance diukur dengan work-life balance scale yang terdiri dari empat dimensi yaitu work intereference with personal life (WIPL), personal life interference with work (PLIW), personal life enhancement of work (PLEW) dan work enhancement of personal life (WEPL). Data di dalam penelitian ini diperoleh dengan menggunakan kuesioner online dengan metode accidental sampling. Penelitian ini melibatkan 172 karyawan generasi milenial (20 - 40 tahun) yang bekerja di sektor perbankan Jakarta. Hasil penelitian menunjukkan bahwa dimensi WIPL (57,6\% ) dan PLIW (54,1\%) generasi milenial berada dalam kategori rendah. Sedangkan dimensi WEPL $(63,4 \%)$ dan PLEW (54,7\%) berada dalam kategori tinggi. Secara khusus work-life balance dapat menjadi preferensi bagi perusahaan dan generasi milenial untuk meningkatkan kualitas pekerjaan dan kesejahteraan individu. Hal ini akan berdampak pada peningkatan kualitas kerja dan kinerja yang tinggi serta dapat juga menjadi prediktor meminimalkan terjadinya fraud di pekerjaan khususnya di sektor perbankan.
\end{abstract}

Kata Kunci: work-life balance, generasi millenial, karyawan perbankan

\begin{abstract}
Millennial generation do not only focus only on high earning, but they also consider the balanced condition between work life balance and personal life. The aim of this research is to investigate the dimensions of work-life balance on millennial generation of workers in the banking sector. The variable of work-life balance measured by using work-life balance scale which consists of four dimensions which are work interference with personal life (WIPL), personal life interference with work (PLIW), personal life enhancement of work (PLEW) and work enhancement of personal life (WEPL). Data obtained using online questionnaire with the use of accidental sampling method. This research involving 172 millennial workers (20-40 years old) that work in the banking sector in Jakarta. The finding of this research showed that dimension of WIPL (57,6\%) and PLIW $(54,1 \%)$ of millennial generation tend to be low. While, the dimension of WEPL $(63,4 \%)$ and PLEW $(54,7 \%)$ tend to be high. It can be said that work life balance can be preference for companies and millennial generation in increasing work quality and the welfare of the individual.
\end{abstract}

Keywords: work-life balance, millennial generation, banking employees

\section{PENDAHULUAN}

Generasi milenial saat ini menjadi fokus perhatian bagi perusahaan ataupun organisasi bukan hanya karena jumlahnya yang meningkat di tempat kerja, tetapi juga karena terdapat perbedaan karakteristik dan sudut pandang dengan generasi sebelumnya. Dalam dunia pekerjaan generasi milenial memiliki etika dalam bekerja yang dikarakteristikkan dengan berorientasi pada hasil, senang bekerjasama dengan orang lain, mencari pekerjaan yang lebih tepat untuk dirinya (Harber, 2011) dan memiliki waktu yang cukup bebas adalah sumber penting kesejahteraan di tempat kerja (Kultalahti \& Viitala, 2014). Nnambooze \& Parumasur (2016) menyebutkan bahwa terdapat beberapa faktor penting bagi generasi milenial dalam bekerja yaitu gaji, apresiasi terhadap pekerjaan, jadwal kerja yang fleksibel (work-life balance), serta career advancement. Selain itu generasi milenial juga memperhatikan fleksibilitas 
dalam aspek work-life balance dibandingkan dengan generasi-generasi sebelumnya (Meier, Austin \& Crocker, 2010).

Hasil survei yang dilakukan oleh Deloite (2018) di Amerika serikat tentang faktor penentu generasi milenial dalam memilih pekerjaan menemukan bahwa faktor utamanya adalah worklife balance. Hasilnya mengatakan bahwa $72 \%$ responden menganggap Work-life Balance menjadi faktor yang sangat penting ketika memilih pekerjaan. Selain itu, 78\% responden wanita lebih tinggi dibandingkan pria sebesar $67 \%$ dalam menentukan faktor work-life balance pada saat memilih pekerjaan.

Work-life balance merupakan upaya yang dilakukan oleh individu untuk menyeimbangkan dua peran atau lebih yang dijalani terkait dengan waktu, energi, pencapaian tujuan dan tekanan (Fisher, 2001). Istilah work-life balance mengacu pada individu yang menghabiskan waktu yang cukup di pekerjaan mereka sementara juga menghabiskan waktu yang cukup untuk kegiatan lain, seperti keluarga, hobi, dan keterlibatan di masyarakat (Smith, 2010). Pada intinya work-life balance adalah tentang membantu menyeimbangkan tanggung jawab individu untuk bekerja dan untuk kehidupannya (Kurmayeva et al., 2014).

Work life balance saat ini telah menjadi konsep penting karena waktu yang terbatas, beban kerja yang meningkat, kebalikan dari peran gender, permasalahan etika/moral, biaya kesehatan di masyarakat, masalah ekonomi/sosial dan akhirnya berkaitan dengan kualitas kehidupan-kerja (Kurmayeva, dkk., 2014). Perkembangan paradigma tentang kesetaraan gender di tempat kerja, rumah tangga yang memiliki penghasilan ganda, dan keluarga dengan orang tua tunggal membuat indivdu memiliki waktu yang terbatas untuk berada dirumah. Kondisi ini membuat individu menghabiskan terlalu banyak waktu di tempat kerja dan tidak memiliki waktu yang cukup untuk melakukan aktivitas yang disukai sehingga akan menimbulkan stres, kepuasan hidup menurun, kesehatan yang memburuk, menurunnya angka produktivitas dan kinerja (Groner, 2018). Oleh karena itu work life balance yang terbentuk pada individu terlepas dari atribut kesuksesan, kekayaan, atau kemiskinan seseorang. Setiap individu mampu memiliki jumlah waktu yang sama setiap hari untuk dialokasikan ke pekerjaan, keluarga, dan kegiatan lainnya (Smith, 2010).

Rife dan Hall (2015) mengatakan bahwa $70 \%$ orang memiliki work life balance yang tidak sehat, namun $70 \%$ orang menjadikan keluarga sebagai prioritas utama dalam kehidupan. Hal ini menunjukkan bahwa setiap individu ingin memiliki work life balance akan tetapi sulit untuk dilakukan karena berbagai komitmen yang harus dilakukan di tempat kerja. Konflik work-life balance yang tinggi pada karyawan membuat karyawan kurang terlibat dalam pekerjaannya dan cenderung lebih berpartisipasi dalam kegiatan pengembangan karyawan yang lainnya (De Kort, 2017) serta akan mempengaruhi kepuasan kerja, loyalitas terhadap perusahaan, kesejahteraan karyawan (Kumayeva dkk, 2014), komitmen terhadap organisasi, produktivitas dan stres kerja (Darcy, dkk. 2012) serta meningkatkan absensi dan turnover karyawan (Rife \& Hall, 2015).

Penelitian yang dilakukan oleh Novelia, Sukhirman dan Hartana (2013) mendapatkan hasil bahwa Personal Life Interference With Work (PLIW) merupakan prediktor utama dari dimensi work-life balance terhadap komitmen berorganisasi pegawai perempuan. Hasil temuan tersebut menunjukkan bahwa kehidupan pribadi dapat mengganggu pekerjaan pada pegawai perempuan yang akan mempengaruhi tingkat komitmen organisasi ke perusahaan.

Work-Life Balance berhubungan dengan adanya kesesuaian antara waktu dan usaha dalam bekerja dan menjalani berbagai aktivitas diluar pekerjaan untuk mencapai kehidupan yang harmonis (Clark, 2000). Definisi tersebut masih cukup luas, sehingga Fisher (2001) memberikan definisi worklife balance sebagai upaya yang dilakukan oleh individu untuk menyeimbangkan dua peran atau lebih yang dijalani terkait dengan waktu, energi, pencapaian tujuan dan tekanan. Berdasarkan penjelasan dan definisi work-life balance tersebut, maka dapat disimpulkan bahwa work-life balance merupakan kemampuan individu untuk menyeimbangkan komponen waktu, energi dan tekanan dalam domain lingkungan pekerjaan dan kehidupan pribadi serta bermasyarakat yang mencakup hobi, studi, olahraga dan volunteerism.

Fisher, Bulger, dan Smith (2009) mengatakan bahwa terdapat empat dimensi pembentuk work-life balance, yaitu:

1. Work Interference With Personal Life Mengacu pada sejauh mana pekerjaan dapat mengganggu kehidupan pribadi individu. Misalnya, bekerja dapat membuat seseorang sulit mengatur waktu untuk kehidupan pribadinya.

2. Personal Life Interference With Work Mengacu pada sejauh mana kehidupan pribadi individu mengganggu kehidupan pekerjaannya. Misalnya, apabila individu memiliki masalah di dalam kehidupan pribadinya, hal ini dapat mengganggu kinerja individu pada saat bekerja.

3. Personal Life Enhancement Of Work Mengacu pada sejauh mana kehidupan pribadi seseorang dapat meningkatkan performa individu dalam dunia kerja. Misalnya, apabila individu merasa senang dikarenakan kehidupan pribadinya menyenangkan maka hal ini dapat membuat suasana hati individu pada saat bekerja menjadi menyenangkan. 
4. Work Enhancement Of Personal Life Mengacu pada sejauh mana pekerjaan dapat meningkatkan kualitas kehidupan pribadi individu. Misalnya keterampilan yang diperoleh individu pada saat bekerja, memungkinkan individu untuk memanfaatkan keterampilan tersebut dalam kehidupan seharihari.

\section{METODE PENELITIAN}

Responden. Penelitian ini melibatkan 172 karyawan generasi milenial yang bekerja di sektor perbankan wilayah Jakarta dengan kriteria sebagai berikut: berusia 20-40 tahun, memiliki pengalaman bekerja minimal satu tahun dan tercatat sebagai karyawan aktif di sektor perbankan.

Desain Penelitian. Penelitian ini menggunakan metode pendekatan kuantitatif deskriptif, yaitu penelitian yang dilakukan dengan tujuan mengetahui nilai variabel independen tanpa dihubungkan atau membuat perbandingan dengan variabel lain (Sugiyono, 2012). Berdasarkan penjelasan tersebut, maka penelitian ini dimaksudkan untuk memperoleh gambaran work-life balance melalui identifikasi dimensi-dimensi work-life balance pada karyawan generasi milenial di sektor perbankan.
Berdasarkan hasil pengujian nilai realibilitas Cronbach's Alpha pada setiap dimensi work-life balance didapatkan nilai, yaitu: dimensi WIPL sebesar 0.812, dimensi PLIW sebesar 0.758, dimensi PLEW sebesar 0.833 dan dimensi WEPL sebesar 0.743 .

Instrumen. Kuesioner yang digunakan dalam penelitian ini adalah work-life balance scale dari Fisher, Bulger dan Smith (2009). Skala ini menggunakan skala Likert dengan 5 pilihan jawaban, yaitu: Tidak Pernah, Jarang, Terkadang, Sering dan Sangat Sering.

Teknik Analisis. Teknik analisis yang dilakukan dalam penelitian ini yaitu descriptive statistic. Teknik descriptive statistic dilakukan terhadap semua item pada setiap dimensi work-life balance untuk melihat item dominan dengan nilai mean tertinggi pada setiap dimensi.

\section{HASIL DAN PEMBAHASAN}

Gambaran Responden Penelitian. Responden dalam penelitian ini melibatkan 172 karyawan generasi milenial yang bekerja di sektor perbankan Jakarta. Data demografik dapat dilihat pada tabel 1 .

Tabel 1. Data Demografi Responden Penelitian

\begin{tabular}{|l|l|c|c|}
\hline & & Frekuensi & Persentase \\
\hline Jenis Kelamin & Laki-laki & 70 & $40.7 \%$ \\
\hline & Perempuan & 102 & $59.3 \%$ \\
\hline Status Pernikahan & Sudah Menikah & 40 & $23.3 \%$ \\
\hline Pendidikan Terakhir & Belum Menikah & 132 & $76.7 \%$ \\
\hline & SMA/SMK & 33 & $19.2 \%$ \\
\hline & Diploma & 28 & $16.3 \%$ \\
\hline & S1 & 108 & $62.8 \%$ \\
\hline Status Pernikahan & S2 & 3 & $1.7 \%$ \\
\hline & Tetap & 55 & $32.0 \%$ \\
\hline Lama Bekerja & Kontrak & 117 & $68.0 \%$ \\
\hline & $<3$ tahun & 136 & $79.1 \%$ \\
\hline & $3-10$ tahun & 25 & $14.5 \%$ \\
\hline Rata-rata Penghasilan & $>10$ tahun & 11 & $6.4 \%$ \\
\hline & Rp $3.000 .000-\mathrm{Rp} 6.000 .000$ & 144 & $83.7 \%$ \\
\hline & Rp $6.000 .000-\mathrm{Rp} 8.000 .000$ & 16 & $9.3 \%$ \\
\hline
\end{tabular}

Sumber: Hasil Olahan Peneliti (2020)

Hasil Pengukuran Variabel. Berdasarkan kategorisasi work-life balance pada karyawan generasi milenial yang bekerja di sektor perbankan wilayah Jakarta dapat dilihat pada tabel 2: 
Tabel 2. Kategori Work-Life Balance

\begin{tabular}{|c|c|c|c|}
\hline & & Frekuensi & Persentase \\
\hline \multirow[t]{2}{*}{ WIPL } & Rendah & 99 & $57.6 \%$ \\
\hline & Tinggi & 73 & $42.4 \%$ \\
\hline \multirow[t]{2}{*}{ PLIW } & Rendah & 93 & $54.1 \%$ \\
\hline & Tinggi & 79 & $45.9 \%$ \\
\hline \multirow[t]{2}{*}{ WEPL } & Rendah & 63 & $36.4 \%$ \\
\hline & Tinggi & 109 & $63.4 \%$ \\
\hline \multirow[t]{2}{*}{ PLEW } & Rendah & 78 & $45.3 \%$ \\
\hline & Tinggi & 94 & $54.7 \%$ \\
\hline \multicolumn{2}{|c|}{ Total } & 172 & $100 \%$ \\
\hline
\end{tabular}

(Sumber: Hasil Olahan Peneliti, 2020)

Berdasarkan tabel 2, kategori dapat dilihat bahwa dimensi-dimensi work-life balance yang bersifat menggaggu (interference) mayoritas berada dalam kategori rendah. Hasil tersebut dapat dilihat bahwa dimensi WIPL sebanyak 99 orang berada dalam kategori rendah (57.6\%), sedangkan dimensi PLIW sebanyak 93 orang berada dalam kategori rendah. Hasil ini dapat dianalisis bahwa pekerjaan dan kehidupan pribadi tidak mengganggu tingkat work-life balance individu dalam kehidupan seharihari.
Sedangkan pada dimensi-dimensi work-life balance yang bersifat meningkatkan (enhancement) mayoritas berada dalam kategori tinggi. Hasil tersebut dapat dilihat bahwa dimensi WEPL sebanyak 109 orang berada dalam kategori tinggi (63.4\%), sedangkan dimensi PLEW sebanyak 94 orang berada dalam kategori tinggi $(54.7 \%)$. Hasil ini dapat dianalisis bahwa work-life balance generasi milenial disektor perbankan dapat meningkatkan kualitas kehidupan pribadi dan pekerjaan.

Tabel 3. Item Work-Life Balance Scale

\begin{tabular}{|c|c|c|c|c|c|c|c|}
\hline No. & Item & $\mathrm{M}$ & SD & WIPL & PLIW & PLEW & WEPL \\
\hline 1. & $\begin{array}{l}\text { Ketika pulang kerja, saya merasa lelah untuk } \\
\text { melakukan berbagai hal lain yang ingin saya } \\
\text { lakukan }\end{array}$ & 2.45 & 1.05 & 0.745 & & & \\
\hline 2. & $\begin{array}{l}\text { Pekerjaan membuat saya merasa sulit untuk } \\
\text { mengelola kehidupan pribadi yang saya } \\
\text { inginkan }\end{array}$ & 3.28 & 1.32 & 0.721 & & & \\
\hline 3. & $\begin{array}{l}\text { Saya sering mengabaikan kebutuhan pribadi } \\
\text { saya karena tuntutan pekerjaan }\end{array}$ & 3.40 & 1.05 & 0.735 & & & \\
\hline 4. & $\begin{array}{l}\text { Kehidupan pribadi saya terabaikan karena } \\
\text { pekerjaan saya }\end{array}$ & 3.45 & 1.16 & 0.727 & & & \\
\hline 5. & $\begin{array}{l}\text { Saya harus kehilangan aktivitas pribadi yang } \\
\text { penting karena jumlah waktu yang saya } \\
\text { habiskan pada pekerjaan }\end{array}$ & 3.63 & 1.16 & 0.736 & & & \\
\hline 6. & $\begin{array}{l}\text { Kehidupan pribadi saya menghabiskan energi } \\
\text { yang saya butuhkan untuk melakukan pekerjaan } \\
\text { saya }\end{array}$ & 3.06 & 1.16 & & 0.744 & & \\
\hline 7. & $\begin{array}{l}\text { Pekerjaan saya terabaikan karena semua hal } \\
\text { yang terjadi dalam kehidupan pribadi saya }\end{array}$ & 3.34 & 1.32 & & 0.735 & & \\
\hline 8. & $\begin{array}{l}\text { Jika bukan karena kebutuhan yang harus saya } \\
\text { lakukan dalam kehidupan pribadi, saya akan } \\
\text { mencurahkan lebih banyak waktu saya dalam } \\
\text { bekerja }\end{array}$ & 3.35 & 0.98 & & 0.785 & & \\
\hline 9. & $\begin{array}{l}\text { Saya terlalu lelah untuk melakukan pekerjaan } \\
\text { dengan efektif di tempat kerja karena suatu hal } \\
\text { yang harus saya lakukan dalam kehidupan } \\
\text { pribadi saya }\end{array}$ & 3.22 & 1.17 & & 0.741 & & \\
\hline 10. & $\begin{array}{l}\text { Ketika saya bekerja, saya khawatir dengan hal- } \\
\text { hal yang harus saya lakukan di luar pekerjaan }\end{array}$ & 3.18 & 1.10 & & 0.740 & & \\
\hline 11. & $\begin{array}{l}\text { Saya mengalami kesulitan untuk menyelesaikan } \\
\text { pekerjaan di tempat kerja karena saya sibuk } \\
\text { dengan permasalahan pribadi saya }\end{array}$ & 4.17 & 0.92 & & 0.748 & & \\
\hline 12. & $\begin{array}{l}\text { Pekerjaan memberikan saya energi untuk } \\
\text { mengejar aktivitas di luar pekerjaan yang } \\
\text { penting bagi saya }\end{array}$ & 3.36 & 1.05 & & & 0.772 & \\
\hline
\end{tabular}

http://ejournal.bsi.ac.id/ejurnal/index.php/widyacipta 


\begin{tabular}{|c|l|c|c|c|c|c|}
\hline 13. & $\begin{array}{l}\text { Pekerjaan saya membuat saya memiliki suasana } \\
\text { hati yang lebih baik di rumah }\end{array}$ & 3.31 & 1.00 & 1.06 & 0.772 & 0.773 \\
\hline 14. & $\begin{array}{l}\text { Aktivitas yang saya lakukan di tempat kerja } \\
\text { membantu saya dalam menangani masalah- } \\
\text { masalah pribadi dan praktis di rumah }\end{array}$ & 3.26 & 0.91 & & 0.773 \\
\hline 15. & $\begin{array}{l}\text { Saya merasa suasana hati saya ditempat kerja } \\
\text { lebih baik karena hal-hal lain yang terjadi di } \\
\text { hidup saya berjalan dengan baik }\end{array}$ & 3.38 & 0.90 & & & 0.758 \\
\hline 16. & $\begin{array}{l}\text { Kehidupan pribadi memberikan saya energi } \\
\text { untuk melakukan pekerjaan saya }\end{array}$ & 3.73 & 0.97 & & 0.754 \\
\hline 17. & $\begin{array}{l}\text { Kehidupan pribadi saya membantu saya untuk } \\
\text { rileks dan merasa siap untuk bekerja di hari } \\
\text { berikutnya }\end{array}$ & 3.55 & & & & \\
\hline
\end{tabular}

Sumber: Hasil Olahan Peneliti (2020)

Analisis deskriptif dilakukan terhadap setiap item pada dimensi-dimensi work-life balance yaitu dimensi work interference with personal life (WIPL), personal life interference with work (PLIW), personal life enhancement of work (PLEW) dan work enhancement of personal life (WEPL). Berdasarkan perhitungan statitistik deskriptif didapatkan hasil bahwa nilai mean tertinggi di item nomor $11(\mathrm{M}=4,17)$ pada dimensi PLIW, yaitu: "Saya mengalami kesulitan untuk menyelesaikan pekerjaan di tempat kerja karena saya sibuk dengan permasalahan pribadi saya". Hasil ini menggambarkan bahwa secara keseluruhan generasi milenial yang kurang mampu menyelesaikan permasalahan pribadinya maka akan menghasilkan kualitas pekerjaan yang kurang maksimal. Kondisi tersebut akan berdampak pada karyawan yang kurang fokus terhadap target dan pekerjaan, motivasi bekerja menjadi menurun serta terjadi ketidakpuasaan dalam bekerja.

Analisis pada item dimensi WIPL didapatkan hasil bahwa nilai mean tertinggi di item nomor 5 $(3,63)$, yaitu: "Saya harus kehilangan aktivitas pribadi yang penting karena jumlah waktu yang saya habiskan pada pekerjaan". Hasil tersebut dapat diinterpretasikan bahwa karayawan yang terlalu sibuk dengan aktivitas didalam pekerjaan seperti meeting, deadline dan lembur dapat menurunkan kualitas kehidupan pribadi seperti berkurangnya waktu terhadap keluarga dan sahabat serta meninggalkan hobi yang dimiliki.

Selanjutnya analisis pada item dimensi PLEW didapatkan hasil bahwa nilai mean tertinggi di item nomor 12 (3,36), yaitu: "Pekerjaan memberikan saya energi untuk mengejar aktivitas di luar pekerjaan yang penting bagi saya". Hasil tersebut dapat di interpretasikan bahwa generasi milenial menjadikan pekerjaan sebagai motivasi, semangat dan dorongan dalam melakukukan aktivitas diluar pekerjaan. Selain itu generasi milenial memiliki beberapa aktivitas dan target yang ingin dicapai selain pekerjaannya saat ini.

Analisis pada item dimensi WEPL didapatkan hasil bahwa nilai mean tertinggi di item nomor 16 (3,73), yaitu: "Kehidupan pribadi memberikan saya energi untuk melakukan pekerjaan saya". Hasil tersebut dapat di interpretasikan bahwa generasi milenial yang mampu mengontrol kualitas kehidupan pribadi seperti hubungan, keluarga, finansial dan pencapaian dalam hidup serta profesional dalam mengelola emosi di lingkungan pekerjaan akan membantu generasi milenial dalam meningkatkan kualitas pekerjaan yang dihasilkan. Item ini juga dapat menggambarkan bahwa karyawan yang mampu bekerja dengan passion dan cinta yang dimiliki akan lebih mampu untuk achieve di lingkungan pekerjaan dibandingkan dengan generasi milenial yang hanya melakukan pekerjaan tanpa adanya passion, cinta dan dorongan dalam pekerjaan tersebut.

Hasil identifikasi pada setiap dimensidimensi work-life balance yaitu work interference with personal life (WIPL), personal life interference with work (PLIW), personal life enhancement of work (PLEW) dan work enhancement of personal life (WEPL) menunjukkan bahwa item 11 pada dimensi PLIW memiliki nilai mean tertinggi (4.17) "saya mengalami kesulitan untuk menyelesaikan pekerjaan di tempat kerja karena saya sibuk dengan permasalahan pribadi saya". Hasil ini sesuai dengan tujuan dari penulis bahwa permasalahanpermasalahan pribadi yang dimiliki oleh setiap generasi milenial dapat mempengaruhi kualitas pekerjaan individu dalam lingkungan pekerjaan.

Analisis pada item dimensi WIPL didapatkan hasil bahwa nilai mean tertinggi di item nomor 5 (3,63). Hasil tersebut dapat di interpretasikan bahwa generasi milenial yang terlalu sibuk dengan aktivitas didalam pekerjaan dan tidak memiliki waktu yang cukup untuk melakukan aktivitas yang disukai maka akan menimbulkan stres, kepuasan hidup menurun, kesehatan yang memburuk, menurunnya angka produktivitas dan kinerja (Groner, 2018). Kondisi tersebut mendorong perusahaan agar mampu menjaga work life balance karyawannya sehingga dapat dijadikan sebagai sebuah strategi yang menguntungkan kedua belah pihak, di mana karyawan akan menjaga komitmen serta meningkatkan performa kerjanya sedangkan 
perusahaan dapat memperoleh hasil yang baik dari kinerja karyawannya (Wasay, dalam Syed, 2015).

Seorang karyawan dapat mencapai work-life balance apabila berada dalam kepuasan dan kebahagiaan baik di tempat kerja ataupun diluar tempat kerja tanpa adanya konflik satu dengan yang lainnya (Kumar \& Krishnan, 2005). Pernyataan tersebut sesuai dengan hasil analisis pada item PLEW yaitu "pekerjaan memberikan saya energi untuk mengejar aktivitas di luar pekerjaan yang penting bagi saya". Generasi milenial menjadikan pekerjaan sebagai motivasi untuk melakukan aktivitas diluar pekerjaan seperti keluarga, hobi dan keterlibatan dalam masyarakat. Oleh karena itu work life balance yang terbentuk pada individu terlepas dari atribut kesuksesan, kekayaan, atau kemiskinan seseorang (Smith, 2010).

Generasi milenial juga memiliki keyakinan bahwa work-life balance dapat diwujudkan di dalam lingkungan pekerjaan (Deloitte, 2018). Pendapat ini sejalan dengan hasil analisis pada item dimensi WEPL yaitu "kehidupan pribadi memberikan saya energi untuk melakukan pekerjaan saya”. Kondisi tersebut mendorong generasi milenial untuk mampu mengontrol kualitas kehidupan pribadi seperti hubungan, keluarga, finansial dan pencapaian dalam hidup serta profesional dalam mengelola emosi di lingkungan pekerjaan yang akan membantu generasi milenial dalam meningkatkan kualitas pekerjaan yang dihasilkan. Hasil tersebut sesuai deng preferensi milenial bahwa memiliki waktu yang cukup bebas adalah sumber penting kesejahteraan di tempat kerja (Kultalahti \& Vitala, 2014).

Perusahaan yang mampu menciptakan dan mengelola work-life balance dapat menjadi sebuah strategi simbiosis mutualisme antara karyawan dengan perusahaan. Penerapan work-life balance dapat melalui kebijakan-kebijakan yang dikeluarkan oleh perusahaan ataupun menciptakan lingkungan bekerja yang mampu mendukung terciptanya kondisi work-life balance. Menurut Singh dan Khana (2011) memberikan strategi bagi perusahaan-perusahaan untuk menciptakan work-life balance bagi karyawan seperti: jam kerja yang fleksibel dan masuk akal, kemudahan dalam menerima telepon atau pesan mendesak dari keluarga di tempat kerja dan akses untuk penanganan anak di kantor bagi yang membutuhkan. Kondisi tersebut sesuai dengan karakteristik generasi milenial di Indonesia yang bersifat komunal serta memiliki aktualisasi diri yang tinggi terhadap aktivitas sosial dan hobi diluar pekerjaan.

\section{KESIMPULAN}

Berdasarkan hasil perhitungan statistik deskriptif pada dimensi-dimensi work-life balance karyawan generasi milenial di sektor perbankan didapatkan hasil bahwa dimensi-dimensi work-life balance yang bersifat menurunkan atau mengganggu (interference) terbentuknya work-life balance tergolong ke dalam kategori rendah $(57,6 \%$ dan $54,1 \%)$. Sedangkan dimensi-dimensi work-life balance yang bersifat meningkatkan (enhancement) tergologong ke dalam kategori tinggi $(63,4 \%$ dan $54,7 \%)$. Secara khusus generasi milenial yang kurang mampu menyelesaikan permasalahan pribadinya maka akan menghasilkan kualitas pekerjaan yang kurang maksimal serta akan berdampak pada karyawan yang kurang fokus terhadap target dan pekerjaan, motivasi bekerja menjadi menurun serta terjadi ketidakpuasaan dalam bekerja. Sedangkan karayawan yang terlalu sibuk dengan aktivitas didalam pekerjaan seperti meeting, deadline dan lembur dapat menurunkan kualitas kehidupan pribadi seperti berkurangnya waktu terhadap keluarga dan sahabat serta meninggalkan hobi yang dimiliki.

Generasi milenial menjadikan work-life balance sebagai motivasi, semangat dan dorongan dalam melakukukan aktivitas diluar pekerjaan yang berkaitan dengan target yang ingin dicapai selain pekerjaannya saat ini. Selain itu, generasi milenial melihat work-life balance sebagai sesuatu yang penting untuk mengontrol kualitas kehidupan pribadi seperti hubungan, keluarga, finansial dan pencapaian dalam hidup yang akan terlihat dalam peningkatan kualitas pekerjaan yang dihasilkan. Hal ini dapat digambarkan bahwa perlunya perwujudan passion dan cinta dari generasi milenial dalam bekerja untuk achieve di lingkungan pekerjaan.

\section{REFERENSI}

Andriani, P. (2017). Pengaruh Dimensi-Dimensi Work-Life Balance Terhadap Keterlekatan Karyawan Generasi $X$ dan $Y$ di Indonesia. Institut Pertanian Bogor.

Darcy, C., McCarthy, A., Hill, A., \& Grady, G. (2012). Work-Life Balance: One Size Fits All? An Exploratory Analysis of the Differential Effects of Career Stage. European Management Journal, 30(2), 111-120.

De Kort, M. (2017). The Relationship between Work-Life Balance, Work Engagement and Participation in Employee Development Activities: A Moderated Mediation Model. Tilburg University.

Deloitte. (2018). Deloitte Millennial Survey: Millennials Dissapointed in Business, Unprepared for Industry 4.0. Retrieved October 15, 2019, from 
https://www2.deloitte.com/content/dam/Deloit te/global/ Documents/About-Deloitte/gx2018-millennial-survey-report.pdf

Fisher, G. G. (2001). Work/Personel Life Balance: A Construct Development Study.

Fisher, Smith, \& B. (2009). Beyond Work and Family: A Measure of Work/Non-Work Interference and Enhancement. Journal of Occupational Health Pyschology, 14(4), 441456.

Groner, E. S. (2018). The Effect of Organizational Culture on Work-Life Balance. Student Publications, 643.

Harber, J. G. (2011). Generation in the Workplace: Similarities and Differences. School of Graduate Studies East Tennessee State University.

Kultalahti, S. \& Liisa, V. R. (2014). Sufficient Challenges and a Weekend Ahead-Generation Y Describing Motivation at Work. Journal of Organizational Change Management, 27(4), 569-582.

Kumar, A. C. S. \& Krishman, S. K. (2005). Balancing Work \& Life - The New Age Dilemma. Human Capital, 9(3), 49-53.

Kurnayeva, et al. (2014). Organizational Culture's Influence on Work Life Balance. Prepare for TBS 903 .

Meier, M. J., Austin F. \& Crocker, M. C. (2010). Generation $\mathrm{Y}$ in the Workforce: Managerial Challenges. The Journal of Human Resource and Adult Learning, 6(1), 68-78.
Nnambooze, B. E. \& Parumasur, S. B. (2016). Understanding the Multigenerational Workforce: Are the Generations Significantly Different of Similar. Corporate Ownership and Control, 13(2), 244-257.

Novelia, P., Sukhirman, I., \& Hartana, G. (2013). Hubungan antara Work/Life Balance dan Komitmen Berorganisasi Pada Pegawai Perempuan. Jurnal Universitas Indonesia, 119.

Rife, A. A., \& Hall, R. J. (2015). Work-Life Balance: A White Paper Prepared by the Visibility Commitee of the Society for Industrial and Organizational Psychology. SIOP White Paper Series.

Singh, M. P. \& Khanna, P. (2011). Work-Life Balance: A Tool for Increased Employee Productivity and Retention. Lachoo Management Journal, 2(2), 188-206.

Smith, K. T. (2010). Work-Life Balance Perspectives of Marketing Professionals in Generation Y. Services Marketing Quarterly, 31(4), 434-447.

Sugiyono. (2012). Memahami Penelitian Kualitatif. Bandung: Alfabeta.

Syed, J. (2015). Work-Life Balance. London: Sage. 